\title{
Grandesertão.Br: O romance de formação do Brasil
}

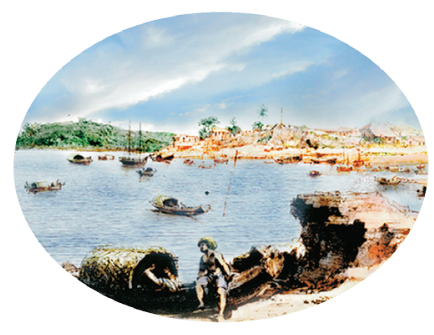

Renan Freitas Pinto*

Como relata Willi Bolle em sua palestra Da metrópole Berlim para a megacidade São Paulo, foi o romance Grande Sertão: Veredas, de Guimarães Rosa que o motivou a vir para o Brasil. Na verdade, a decisão foi tomada logo após o curso que o prof. Antonio Soares Amora tinha no primeiro semestre de 1966 na Universidade Livre de Berlim sobre Grande Sertão: Veredas.

Nesse mesmo ano, depois de uma viagem de navio que durou vinte dias, o jovem estudante alemão chegou ao Brasil para dar início ao seu projeto de estudar a obra de Guimarães Rosa que tanto o impressionara, o que na verdade foi também o caminho escolhido para estudar e buscar compreender o Brasil.

Para ter um contato mais aprofundado com a obra, revela seu método, sem dúvida singular, ou seja, passou a viver "dentro do livro", pois havia forrado as paredes de seu quarto com aproximadamente 500 páginas do romance, método que voltou a usar, anos depois, na Universidade de Stanford, onde elaborou o primeiro esboço do livro grande sertão.br: $\mathrm{O}$ romance de formação do Brasil.

Já em forma de livro publicado, o ensaio de Willi Bolle intencionalmente coloca diante de seus leitores alguns momentos inesperados e de surpresa que funcionam como os sinais de atenção numa estrada.

\footnotetext{
* Possui doutorado em Ciências Sociais pela Pontifícia Universidade Católica de São Paulo (1992). Atualmente é professor titular da Universidade Federal do Amazonas. E-mail: erfpinto@gmail.com
} 
O primeiro desses sinais já o encontramos, mesmo antes de começarmos a viagem da leitura, pois o descobrimos na ficha de apresentação do livro, na qual, entre as palavras-chave está a palavra educação.

Outro sinal de atenção, este já em plena leitura, é a proposição do romance de Guimarães Rosa como um hipertexto, como um website dedicado aos discursos sobre o Brasil, uma narração em forma de rede, sendo uma das tarefas do ensaio decifrar essas redes.

Uma outra sugestão da leitura como um jogo de armar (e de desarmar) é a narrativa labiríntica da obra.

A leitura de grande sertão.br: O romance de formação do Brasil, nos convida, estimulados pelos vários significados que o autor nos revela, a empreender uma reflexão em múltiplas direções, praticamente todas elas sugeridas já a partir do subtítulo, mas também algumas outras brotando e reaparecendo em várias alturas de seu ensaio, concebido e realizado como a visualização de uma constelação de significados e de interrogações sobre a obra de Guimarães Rosa.

A leitura do ensaio nos fez também imediatamente lembrar uma afirmação de Theodor Adorno que está em sua obra A Filosofia da Nova Música, relacionada com as potencialidades das formas de arte, no sentido de que estas "registram a história da humanidade com mais exatidão do que os documentos". Assim pareceu-nos estar plenamente confirmada a ideia de que uma obra concebida e realizada como texto ficcional é capaz de se transformar em documento vivo da mentalidade, dos valores e da formação histórica e social de um povo. Da mesma forma que o ensaio como caminho escolhido é o que oferece mais possibilidades de buscas e achados.

A obra de Guimarães Rosa é, portanto, construída a partir de uma perspectiva que "transpõe o horizonte da obra literária". Ou seja, seu projeto poético encerra o que Willi Bolle sugere como uma utopia não apenas estética, mas 'educacional e política", ao reinventar o português do Brasil buscando transformá-lo numa possibilidade para o diálogo no interior da sociedade. Daí se esclarece a presença da palavra-chave educação.

Entre as suas múltiplas expectativas e seus valiosos achados, portanto, o autor descobre uma proposta de educação em Grande Sertão: Veredas, revelando entretanto que ela é estrategicamente negativa, o que implica na 
situação de não propor metas para o futuro, mas uma revolução da linguagem que aparece também como utópica, na medida em que ainda está por ser construída a experiência do diálogo entre as classes.

Sugere que a reinvenção do português do Brasil representa também uma forma de "reescrita da história do Brasil", de, ao mesmo tempo, criptografar e desvendar essa história, o que nos leva a imaginar que insuspeitadas possibilidades poderiam existir a partir de tecnologias que estão apenas em seu começo, mas que estão apontando com muita velocidade em seus exemplos práticos, para sua presença crescente em todas esferas da vida. Nessa perspectiva, as possibilidades criadas pelas tecnologias devem ser vistas como inspiradoras do título do ensaio grandesertão.br: O romance de formação do Brasil.

\section{Releituras das interpretações da formação do Brasil}

No percurso da leitura do ensaio, somos inevitavelmente convidados a reler Guimarães Rosa para redescobrí-lo, na medida em que nossa leitura até então estava fundada essencialmente na ideia de sua obra como recriação de elementos da linguagem de um certo Brasil agrário e rude, transformados esses elementos em uma narrativa fortemente impregnada de sentido poético. Em sentido análogo, somos também conduzidos à releitura d' Os Sertões, não apenas como momento de reflexão esclarecedor sobre o sentido da formação do Brasil, mas, por contraste, como uma possibilidade de compreender com mais clareza o próprio Euclides da Cunha como um intelectual dividido, também ele dilacerado como o País que buscava, a seu modo, decifrar. Ou seja, ao longo dessa leitura hipertextual, simultaneamente, Euclides da Cunha e Guimarães Rosa vão ficando mais claros.

Com grandesertão:br, portanto, seu autor se propõe a realizar uma nova leitura de Grande Sertão: Veredas tendo como referência, vários pontos de partida, a começar pelo amplo conjunto de leituras a que tem sido submetida a obra, buscando aí apontar importantes contribuições, mas sobretudo identificando ausências, caminhos não explorados, que se propõe a enfrentar e percorrer, a partir da ideia dessa obra como um novo retrato do Brasil.

$\mathrm{O}$ autor acredita que o significado de sua investigação será esclarecido 
ao longo da leitura que se propõe a fazer de forma a desvendar aspectos de teor elucidativo que matizam o vasto quadro composto pelos estudos que se produziram e continuam se produzindo em torno da obra maior de Guimarães Rosa, por inúmeras e fortes razões, avaliada como a mais representativa da literatura brasileira do século XX.

Com o objetivo de revelar o sentido da obra investigada como uma nova interpretação do Brasil, empreende um exame de várias das interpretações estabelecidas, para com elas confrontar a interpretação construída ao longo de Grande Sertão: Veredas. Entre essas deve ser destacada sobretudo a de Euclides de Cunha em Os Sertões, mas também as de Gilberto Freyre, Sérgio Buarque de Holanda, Caio Prado Jr, Raymundo Faoro, Antonio Candido Celso Furtado e Darcy Ribeiro, entre os mais reconhecidos como autores de interpretações e invenções do Brasil.

Ao revisar todas essas leituras do Brasilo autor pretende simultaneamente aproveitar, em relação a Grande Sertão: Veredas, "descobertas de todas as tendências da recepção" sem que isso implique em uma simples "somatória de resultados isolados, mas a integração do entendimento das partes à ideia geral". Pretende, além disso, assinalar que. "com um potencial 'sui generis' o romance ocupa em relação àquelas obras [...] canônicas uma posição complementar e concorrente" (p .24).

Como resultado de todo esse investimento hermenêutico, em que são mobilizados "recursos da retórica, da poética e da estilística, pretende-se também chegar a uma compreensão integrada das micro e macroestruturas narrativas. Tudo isso no sentido de desenvolver um estudo crítico que falta, ou seja, uma leitura de Grande Sertão: Veredas como um retrato do Brasil”' (p.2223). Portanto, Guimarães Rosa não apenas como um romancista, mas como um pensador do Brasil.

\section{Uma leitura de Guimarães Rosa a partir de clássicos alemães}

É particularmente forte na construção do ensaio a livre utilização de contribuições de autores da tradição clássica alemã relativos a alguns de seus aspectos norteadores, como o do romance de formação, da hermenêutica do 
texto, da ideia de povo e de história. Nesse sentido estão presentes ideias e conceitos de autores como Friedrich Schlegel, Goethe, Hegel, Schleiermacher e Walter Benjamin, articulados ou contrapostos aos de autores de outras tradições intelectuais que o ensaio arregimenta com extrema precisão e adequação aos seus objetivos e resultados.

São nesse sentido ilustrativas as referências do ensaio a sugestões metodológicas como a de Schleiermacher segundo a qual "o entendimento da relação do escritor com as formas já definidas em sua literatura é um elemento tão essencial da interpretação que sem isso não se pode compreender nem o todo nem as partes". E esse método foi adotado e adaptado à leitura de Grande Sertão: Veredas, a partir do que se evidenciaram determinados elementoschave na obra que a aproximam claramente do gênero retratos do Brasil.

Outro momento especialmente elucidativo do ensaio é aquele em que o autor recorre a Goethe, referindo-se à ideia de que a história necessita ser reescrita de tempo em tempo, para aplicar o princípio também a Grande Sertão: Veredas, a propósito da possibilidade de ser o romance lido não apenas como uma obra literária, mas ser "considerado também como um 'dispositivo' de escrita, ou seja, um programa em aberto” (p.44), uma vez que não é possível saber como será reescrita a obra no futuro.

Ideia que se reveste de um significado fundamental para a construção do ensaio é aquela inspirada em Hegel da "história como tribunal", retomada em vários momentos, a começar pelos sentidos de julgamento da história em Os Sertões e Grande Sertão: Veredas, mas que reaparece com intensidade nas análises voltadas para "o sistema jagunço" e "a nação dilacerada".

São vários os momentos do ensaio em que aparecem referências a ideias de Walter Benjamin, entre as quais possuem particular significado a que trata do método de análise e interpretação da "mitologia da modernidade" no qual ele sugere que a mitologia deve ser dissolvida no espaço da história. Prefere Willi Bolle, entretanto, em lugar de dissolvê-la, "analisá-la, esclarecendo que o pacto com o diabo que acontece em Grande Sertão: Veredas, seguindo a terminologia benjaminiana, seria uma imagem arcaica que, devidamente decifrada, poderia revelar a história originária ou primeva da sociedade.

Sendo a nova historiografia de Benjamin inspirada na teoria da memória 
e do sonho de Sigmund Freud, que "formula o ofício de historiador, em analogia ao do psicanalista, como o de um intérprete dos sonhos coletivos". E esse será, revela o autor do ensaio, "o método que orientará a presente investigação" (p.146).

O investimento hermenêutico que resulta na interlocução do autor com ideias fundadoras da tradição do pensamento moderno, confere ao ensaio sobre o romance roseano uma constelação de possibilidades de leituras reveladoras, que estão sugeridas claramente na nomeação de alguns do capítulos, que vamos a partir daqui apresentar através de alguns dos achados revelados no corpo do ensaio, além daqueles que já apontamos quando nos referimos à obra de Guimarães Rosa na tradição dos retratos do Brasil e acrescentaríamos, na abordagem do sertão como forma de pensamento. Passemos a mencionar brevemente alguns dos aspectos do sistema jagunço, que no ensaio são apresentados em toda sua força interpretativa.

Willi Bolle relata um fato vivido por ele em viagem a Canudos, ocasião em que resolveu ler trechos de Os Sertões para habitantes locais, e que, para não ofender os ouvintes, teve que omitir uma série de expressões que ilustram o tratamento preconceituoso de Euclides da Cunha em relação aos sertanejos, que o escritor insistia em chamar de jagunços.

Por sua vez, "Ao fundamentar seu retrato do Brasil numa encenação do sistema jagunço - instituição no limiar entre a lei e a ilegalidade, onde a transgressão é a regra e a guerra é permanente - Guimarães Rosa representa o funcionamento das estruturas de poder no país" (p.138). E complementa assinalando que “... os principais responsáveis pelo sistema jagunço e pela guerra nesse sertão chamado Brasil não comparecem diante do tribunal da história".

\section{O pacto de Riobaldo com o diabo}

Sabemos existir na tradição literária e teatral - com origem na narrativa popular - várias versões de personagens que selam pactos com o diabo. $\mathrm{O}$ tema reaparece em Grande Sertão: Veredas e seu significado, que já mereceu um sem número de interpretações, aqui é reexaminado tomando-se em conta sua contribuição para revelar aspectos da formação histórica do Brasil, a partir da ideia de que o pacto aqui selado, enquanto alegoria de um falso contrato 
social, representa a lei fundadora que orienta a ação dos poderosos, contra o pano de fundo que expõe a efetiva inexistência de um pacto que tornasse possível a comunicação entre os diferentes setores que assim poderiam se reconhecer como, de algum modo, fazendo parte do todo da Nação.

Além do pacto como alegoria de um falso contrato social, que é representado pela narrativa envolvendo o acerto de Riobaldo com o Diabo, que serve não apenas para o protagonista narrar sua vida, mas, segundo o autor, "traduz a reflexão de Guimarães Rosa a respeito das instituições sobre as quais repousam a ordem pública, o sistema político do País, as estruturas jurídicas do Estado e o próprio processo da modernização" (p. 155).

A função diabólica da linguagem é desempenhada por Riobaldo, quando vive sua iniciação à retórica do poder na condição de chefe de jagunços ao mesmo tempo em que procura rever sua condição anterior, comprometida com uma outra ordem de valores.

E da facilidade com que Riobaldo, jagunço letrado, aprende rápido "a arte de lutar com palavras", de rapidamente se amoldar a novas situações políticas e de se conduzir como um dentre os fazendeiros e latifundiários do sertão, aprimorando também inevitavelmente "a arte de enganar o povo".

$\mathrm{O}$ autor do ensaio, a propósito do aumento do poder de Riobaldo como um seu representante, lança a pergunta: a quem serve a guerra? Para aumentaré a primeira resposta - o poder e as posses dos que já mandam, mas sobretudo para aumentar a desgraça do povo, levando também muitos jagunços à morte e à mendicância.

Procurou o ensaio aprofundar a compreensão dos efeitos do pacto a partir de uma visão de dentro, ou seja, procurando desmontar a encenação do discurso do poder pelo jagunço-letrado e narrador pactário, desnudando a lei fundadora que fornece o cimento não apenas para as ações, mas sobretudo para os discursos do poder.

Com esse personagem o romancista tem a possibilidade de explorar todas as possibilidades de um narrador possuído, de parte com o demônio, e da função diabólica da linguagem. 


\section{Diadorim}

O autor do ensaio se pergunta: o que seria do romance Grande Sertão: Veredas sem Diadorim?

Seria, a seu ver, algo insuportável, com seus outros personagens fazendeiros, a gente simples dos povoados, os jagunços -, sua interminável e brutal guerra entre matadores, e a rotina simplória dos sertanejos, se não passasse pelas suas páginas, "também o sopro de um princípio mais elevado e transformador: a Beleza e o Amor, simbolizados pela figura de Diadorim" (p.195).

A força enigmática dessa figura, a grande paixão do protagonista narrador Riobaldo, confere ao romance vários dos elementos que o transformam nessa realização ficcional capaz de ser lida também como uma reescrita da formação do Brasil, ao propiciar ao leitor os diversos desvendamentos dos personagens que representam as chaves dessa reescrita.

A tradução francesa do romance, publicada com o título de Diadorim serviu para acentuar a posição de sua figura no tablado labiríntico da obra.

É também oportuno lembrar depoimento de Ariano Suassuna sobre uma conversa com Guimarães Rosa em que sugere que Diadorim se inscreve na tradição do romance ibérico em que a donzela vai a guerra, com o que Guimarães Rosa logo se interessou, reconhecendo que "realmente o romance medieval lhe servira de guião para o enredo de seu grande romance guerreiro".

Sobre o primeiro encontro de Riobaldo com Diadorim em travessia do rio São Francisco, ou seja, uma travessia sob a égide do então menino, o personagem se pergunta: "Por que foi que eu precisei de encontrar aquele Menino?” Para o autor do ensaio, não existe resposta para esta pergunta, tratando-se na verdade de um problema constitutivo do romance de formação, como é possível confirmar com o exemplo do encontro do herói com o desconhecido, que está no texto protótipo de Goethe, "Os anos de aprendizagem de Wilhelm Meister".

Vale adiantar aqui alguns aspectos-chave da figura de Diadorim ao ingressar no bando de jagunços chefiados por Riobaldo. O primeiro certamente é o da história de um amor impossível, da paixão inaceitável no interior da 
cultura sertaneja, de um homem por outro homem, que Guimarães Rosa utiliza como uma ironia das qualidades guerreiras, ao sugerir um amor homosexual: "De que jeito eu podia amar um homem, meu de natureza igual, macho em suas roupas e suas armas [...] ?!’. Amor ao qual a própria morte de Diadorim em combate põe termo, além do fato de que Riobaldo, apesar de sua paixão por Diadorim, já definira seu trato de núpcias com Otacília em sua estratégia de se tornar um homem de posses, dono de fazendas, e largar a jagunçagem.

O segundo é a do luto individual do protagonista-narrador pela morte de Diadorim, que é tomado pelo romancista para traçar metaforicamente o "retrato histórico-etnográfico da coletividade" (p.213), retrato esse contraposto à obra de luto que é também Os Sertões.

Com a figura de Diadorim, que personifica a coragem de uma mulher guerreira que se destaca em combate, em meio ao bando de jagunços, Guimarães Rosa desconstrói a heroicidade retórica com a qual é traçado o perfil ideal do sertanejo por Euclides da Cunha.

Sua entrada no mundo jagunço sob o comando de Riobaldo, diferente dos demais, que estão ali sem propósito, apenas cumprindo seu ofício, seu meio de vida, reveste-se da missão de vingar seu pai Joca Ramiro, ou seja, derrotar o poderoso e temido Hermógenes. O que de fato ocorre, mas com o preço da morte de Diadorim e é só nesse momento Riobaldo vai conhecer o segredo, ou seja, de que "Diadorim era o corpo de uma mulher, moça perfeita...".

Se a combinação e oposição dos elementos masculino e feminino em Diadorim costumam estar associados à tradição da donzela guerreira e ao mito do andrógino, há suficientes indicações para sua interpretação como uma figuração do corpo social do povo. Diadorim adivinha, por exemplo, os objetivos de Riobaldo e lhe prenuncia as ambições de tomada de comando, de se tornar proprietário de terras, de casar com a filha do dono de grande fazenda. Mas, diante dos desmandos dos jagunços, sempre toma o partido dos mais fracos e das vítimas. É a partir dessa posição fronteiriça que sua figura expressa, no interior do sistema jagunço, o corpo social do povo. Mas Diadorim, precisamente por sua identificação maior com os que sofrem a violência do sistema personificado pelos chefes, dos fazendeiros aos políticos e governantes, revela também a dificuldade dos letrados em compreender e 
retratar esse enigma maior, o povo.

\section{Um retrato na contramão}

O ensaio parte, ao construir o capítulo A nação dilacerada, do reconhecimento de que está em curso, a formação de uma nação, entretanto uma nação problemática em sua efetivação, na medida em que não se conseguiu estabelecer um pacto profundo entre as classes sociais que compõem o seu corpo. Daí a idéia de uma nação dilacerada, no sentido também, de uma construção político-social fundamente marcada pela violência material e simbólica, pelo sofrimento, desprezo e destituição de parte gigantesca desse corpo assim monstruoso. A partir da linguagem criptografada, mas também do que Willi Bolle muito apropriadamente designa como uma reinvenção da linguagem, o romance Grande Sertão: Veredas nos faz pensar e enxergar, através do poder de sugestão dessa reinvenção, não simplesmente o Brasil representado como estranho, incômodo e grotesco do mundo jagunço e do próprio sertão como descompassada geografia e agressiva paisagem, em contraste com a pretensa e arrogante modernidade e urbanidade, ou seja, das dissimuladoras incompatibilidades entre essas duas faces, na verdade, de um mesmo corpo.

Um dos aspectos mais reveladores do ensaio sobre Grande Sertão: Veredas é o do exame de determinados posicionamentos de obras que se tornaram conhecidas como interpretações do Brasil. De certas ideias que passaram a circular entre nós como traços identificadores de nossa formação. Aqui nos limitaremos a fazer delas algumas referências que são tomadas pelo romance de Guimarães Rosa como objeto de desconstrução.

O grande e preferencial alvo dessa desconstrução, já o indicamos, reside no mais íntimo da obra Os Sertões, cujo exemplar de Guimarães Rosa foi manuseado pelo autor do ensaio, descobrindo aí anotações que serviram em parte para saber o que mais interessou o romancista para transformar em material a servir de roteiro para a sua reescrita. Mas a leitura do ensaio nos leva também a reconsiderar, a partir de autores inventores do Brasil, como Gilberto Freyre, Sérgio Buarque de Holanda, Caio Prado Jr. Celso Furtado, Darcy Ribeiro e Antonio Candido, o quanto o romance Grande Sertão: Veredas, de fato, representa não apenas uma reescrita dessas contribuições da invenção 
do Brasil, mas um ensaio - no sentido de experimento - em direção às suas perspectivas e consumações utópicas futuras.

\section{O ensaio como reinvenção das narrativas}

Procuramos destacar que a forma ensaio escolhida por Willi Bolle para propor a leitura - na verdade, leituras - de Grande Sertão: Veredas como uma nova interpretação das interpretações do Brasil a que estamos acostumados a lembrar e a manusear com frequência, assim como uma reescrita hermenêutica, de decifração da formação do Brasil enquanto nação e povo, da mesma forma que o próprio Guimarães Rosa como preceptor do Brasil, todas essas experiências de investigação e de surpreendentes resultados, tornaram-se possíveis graças a essa escolha de caminho.

O ensaio, como de forma tão convincente o definiu Theodor Adorno em seu $\mathrm{O}$ ensaio como forma, dá asas à liberdade, estimula a ousadia do pensamento, acentua a força do parcial frente ao total, valoriza o fragmento, o efêmero, o cambiante em face dos sistemas de pensamento consagrados.

O ensaio como experimento em aberto, atua sem cerimônia, criando conceitos que se opõem ao que está cristalizado na própria linguagem e contra ela, prossegue em seus movimentos, fazendo com que "o pensamento não proceda linearmente e em um só sentido, mas que seus momentos se entreteçam como os fios de uma tapeçaria".

\section{Referências}

THEODOR W. Adorno: Notas de Literatura. Barcelona: Ediciones Ariel, 1962 . W. Adorno: Filosofia da Nova Música. São Paulo: Editora Perspectiva, 1974.

WILLI Bolle: grandesertão:br: O romance de formação do Brasil. ed. 34. São Paulo: Duas Cidades, 2004.

Bolle: Fórmula e fábula: teste de uma gramática narrativa, aplicada aos contos de Guimarães Rosa. São Paulo: Perspectiva, 1973. 